\title{
UMA PROPOSTA DE PERIODIZAÇÃO PARA OS LIVROS DIDÁTICOS DE GEOGRAFIA NO BRASIL
}

\author{
Gabriel Pinto de Bairro ${ }^{1}$ \\ José Vitor Rossi Souza²
}

Resumo: Este trabalho analisa diferentes periodizações históricas sobre os livros didáticos de Geografia e a Geografia Escolar, as quais servem como ponto de partida para construir uma periodização de modo a integrar elementos da Pedagogia, da Geografia e da política editorial, na tentativa de estabelecer fases da produção de livros didáticos de Geografia no país. O recorte têmporo-espacial compreendeu os séculos XX e XXI, tornando verificável tanto os pontos de convergência entre os três elementos citados e suas influências entre si, quanto o desenvolvimento da política pública nacional de livros didáticos, culminante no Programa Nacional do Livro Didático (PNLD). Como resultados, além da proposta de periodização com uma análise integrativa, para além dos limites impostos pelos três campos, consolidou-se também a abertura de novas possibilidades de investigação através das interfaces observadas.

Palavras-chave: Livro Didático, PNLD, Ensino de Geografia, Pensamento Geográfico, Pedagogia.

\section{A PERIODIZATION PROPOSAL FOR GEOGRAPHY TEXTBOOKS IN BRAZIL}

\begin{abstract}
This article analyzes different historical periodizations of Geography textbooks and Geography Teaching in Brazil, which serve as a starting point to build a periodization in order to integrate elements of Pedagogy, Geography and editorial policy, in an attempt to establish phases of book production geography didactics in the country. The chosen temporal-spatial cut comprised the 20th and 21st centuries, making verifiable both the points of convergence between the three elements mentioned and their influences among themselves, as well as the development of the national public policy on textbooks, culminating in the Brazilian National Textbook Program (PNLD). As a result, in addition to the proposal of a periodization with an integrative analysis beyond the limits imposed by the three fields, the opening of new research possibilities through the observed interfaces was consolidated.
\end{abstract}

Key-words: Textbook, PNLD, Geography Teaching, Geographical Thinking, Pedagogy.

\footnotetext{
${ }^{1}$ Bacharel e licenciado em Geografia, mestrando no Programa de Pós-graduação em Geografia da Unesp (campus Rio Claro). E-mail: gbairro@gmail.com

${ }^{2}$ Licenciado em Geografia, mestrando em Educação no Programa de Pós-graduação em Educação da Unesp (campus Rio Claro). E-mail: jrossisouza@gmail.com
} 


\section{INTRODUÇÃO}

Ao longo da história, percebe-se que os livros didáticos são um artefato que faz parte da cultura escolar e, a depender do contexto, possuem maior ou menor centralidade. De qualquer forma, são considerados como uma obra de grande importância para subsidiar o processo de ensino e aprendizagem, a qual apresenta tanto elementos originais provenientes da cultura escolar quanto conteúdos transpostos da ciência de referência (SENE, 2014). Eles são um importante produto da Geografia escolar, mas historicamente foram vistos como publicações de segunda categoria, aos quais não se deveria dar importância pelo fato de que eram destinados apenas a difundir os ideais das classes dominantes (ALBUQUERQUE, 2014).

Apenas nas últimas décadas que as pesquisas sobre este material escolar, inclusive na área do ensino de Geografia, começaram a ser ampliadas e diversificadas, fato comprovado por algumas publicações (MUNAKATA, 1997; 2012; PINHEIRO, 2005). Isso se deve, entre outros fatores, por ser uma fonte documental que reúne e materializa determinadas características de um contexto educacional e que se constituir como um importante instrumento de auxílio dos professores para organização dos conteúdos programáticos de cursos e disciplinas ministradas pelos mesmos (CHOPPIN, 2000).

Além disso, o livro didático, sendo um tipo de livro, pressupõe também um potencial leitor (CHARTIER, 2002; BOURDIEU, 2004). E os diversos períodos da história da produção didática nacional servem como aferidores de uma produção de didática em suas diversas formas, destinadas para um potencial consumidor. Em momentos de maior embate e disputa pela hegemonia nas ideias educacionais - como, por exemplo no conflito entre os educadores religiosos e os escolanovistas no primeiro quartel do século XX (SAVIANI, 2013) - os livros didáticos foram utilizados como um veículo para que autores pudessem veicular suas ideias e os ideais que pretendiam perpetrar na educação nacional. Ideias estas cujas matrizes foram, ao longo do tempo, importadas e adaptadas à educação do país por autores que se tornavam leitores "tradutores" das teorias à luz da realidade brasileira, utilizando tais referenciais estrangeiros na produção de materiais pedagógicos voltados para formação de professores (SAVIANI, 2013; SILVA, 2018).

Portanto, a relação entre conhecimento contido no livro didático e seus autores marca também a história da leitura destes materiais. Em seu caso específico, tal material escolar carrega em suas laudas a concretude dos momentos educacionais gerais e do desenvolvimento do campo científico específico. Mesmo que os caminhos de investigação sejam diversos (em forma, conteúdo, corrente teórica, entre tantos), faz-se importante evidenciar o caráter histórico do livro didático, demonstrando ainda, na prática, que estes materiais escolares podem servir como base para entender os traços marcantes de uma época educacional no que se refere às ideias pedagógicas, às matrizes do pensamento geográfico e à identidade visual. Inclusive, o livro didático como conhecemos hoje, principalmente aqueles avaliados e distribuídos pelo PNLD, é fruto de um percurso de continuidades e descontinuidades de elementos. É por isso que, quando comparados, identifica-se o que se manteve ao longo do tempo (as permanências), mas também aquilo que foi alterado e os motivos de tal acontecimento. Em outras palavras, defende-se aqui uma "leitura" do livro didático sem desvinculá-lo de seu contexto de produção.

Diante disso, objetivou-se, pois, apresentar, através de uma proposta de periodização, como as metamorfoses ocorridas no livro didático de Geografia estão relacionadas com transformações mais amplas no campo da Educação, das políticas 
públicas, da editoração e também com as rupturas na própria ciência geográfica. E, ao considerar todos esses elementos, será inserido o livro didático de Geografia em seu contexto, já que defendemos que sua análise precisa ser feita levando em conta tanto aspectos específicos (como a visualidade, a disposição dos conteúdos) quanto aspectos mais amplos (como as políticas educacionais, as matrizes do pensamento geográfico e as ideias pedagógicas de cada época).

\section{DIFERENTES PROPOSTAS DE PERIODIZAÇÃO A PARTIR DE DISTINTOS CRITÉRIOS}

Várias seriam as possibilidades de estabelecer uma periodização dos livros didáticos, assim como outros autores já fizeram sobre os livros, bem como da própria trajetória da Geografia escolar. Entre eles destacam-se Azambuja (2014), que faz uma análise (particular) de conteúdo dos livros; Moreira (2014), com uma interpretação do desenvolvimento das correntes do pensamento geográfico, tendo como referência a organização dos livros didáticos de geografia a partir do arquétipo N-H-E; Souza e Pezzato (2010), que estabeleceram uma periodização a partir das ideias pedagógicas e das reformas curriculares influenciadoras na Geografia escolar; e Tonini (2014), cuja periodização se relaciona com a visualidade dos livros.

Assim, propor aqui uma outra forma de periodização não significa desconsiderar as anteriores. Pelo contrário: adota-se cada uma delas como ponto de partida, enquanto metodologia, para definir uma distinta, haja visto a utilização de critérios diferentes como subsídio, mas que de certa forma contemplam os quesitos principais usados individualmente nas periodizações precedentes. Entretanto, acrescentou-se um critério incomum considerado como fundamental para essa investigação: o desenvolvimento da política pública do livro didático no Brasil. Sendo assim, as datas que marcam o início e o fim de cada período têm, como parâmetro prioritário (quando possível), eventos importantes no que se refere às políticas estatais voltadas para a produção e distribuição dos livros didáticos, os quais afetaram diretamente as obras de Geografia.

Recuperando as periodizações evocadas, antes de argumentarmos sobre a proposta neste trabalho, Moreira (2014) propõe uma distinção dos livros em três fases, considerando que eles expressam um diálogo com o fluxograma dos currículos universitários e com os programas oficiais. O ponto de partida está relacionado com o tratamento dado pelos autores das obras ao arquétipo N-H-E, o que delineia três fases do livro didático de Geografia: a clássica, a fase de transição e a fase atual. A primeira tem como um dos principais representantes Aroldo de Azevedo. Em um momento de transição a partir de 1970, a segunda fase caracteriza-se por livros com uma estrutura fragmentária, em que mapas e fotos, que antes apresentavam um caráter formativo e articulado, transformam-se em um recurso apenas de ilustração. Como representantes dessa fase ele cita Guiomar Goulart de Azevedo (do livro "Geografia") e Zoraide Victorello Beltrame (autora de "Investigando o ambiente do homem").

Já a terceira, a fase das inovações, para Moreira (2014) ela evidencia uma diversidade em diferentes sentidos: de orientações intelectuais, de estruturação e formato, de quantidade de livros e também de autores. Nesse novo momento, o arquétipo N-H-E e o modelo estrobono-ptolomaico, ainda marcantes na fase de transição, perdem visibilidade. É nesta em que se inserem autores relacionados ao processo de renovação da Geografia 
brasileira, como Melhem Adas, Sueli Furlan, José William Vesentini, Vânia Vlach, Diamantino Pereira e Douglas Santos.

Por sua vez, uma segunda periodização possível é proposta por Azambuja (2014), que também estabelece três períodos ou tempos de consolidação da Geografia escolar, relacionando-os aos livros didáticos. No primeiro período (início do século XX até a década de 1960) havia a predominância de livros didáticos de autoria, como de Delgado de Carvalho e Aroldo de Azevedo, assim como a afirmação do paradigma geográfico da terra e do homem. No segundo (de 1971 até meados da década de 1990), quando ainda não haviam ocorrido grandes mudanças em relação ao primeiro, observava-se uma diversidade de manuais didáticos de Geografia, às vezes com a manutenção do paradigma geográfico da terra e do homem, inserção de técnicas de estudo dirigido através de exercícios e mudanças teórico-metodológicas advindas da renovação crítica da Geografia. Já no terceiro período (iniciado na segunda metade da década de 1990) os livros passaram a ser elaborados com base nos novos critérios do PNLD.

A terceira proposta de periodização analisada não trata especificamente de livros didáticos e foi feita por Souza e Pezzato (2010), que subdividiram a trajetória da Geografia na escola básica. Ambos adotam como referência a perspectiva da história das disciplinas escolares baseando-se em Chervel (1990), que considera que os conteúdos de ensino são provenientes da escola e não apenas da ciência de referência e, portanto, a disciplina escolar também é produtora de conhecimentos. Os autores destacam que é com a criação do Imperial Colégio Pedro II, em 1837, que tinha como objetivo a difusão do saber oficialmente aceito, que a Geografia adquire, no currículo escolar brasileiro, o estatuto de disciplina autônoma, o que representa um marco importante para o ensino de Geografia no país, não sendo mais apenas um conteúdo disperso no conjunto de conhecimentos ensinados nas escolas (SOUZA; PEZZATO, 2010). Cabe ressaltar que isso não era exclusivo da ciência geográfica, já que a difusão dos saberes até então estava articulada com a influência da política educacional de seu tempo - o que não deixou de ocorrer na virada para o século $\mathrm{XXI}^{3}$.

Quadro 1 - Periodização da trajetória da Geografia escolar no Brasil

\begin{tabular}{|c|l|}
\hline Período & \multicolumn{1}{c|}{ Justificativa da divisão } \\
\hline $1549-1920$ & $\begin{array}{l}\text { Inicia-se com a vinda dos jesuítas ao Brasil, tendo com um dos } \\
\text { objetivos a educação dos colonos e índios, e termina na } \\
\text { década de 1920, período de inserção da Geografia nos } \\
\text { currículos escolares, na Universidade e do movimento Escola } \\
\text { Nova. }\end{array}$ \\
\hline $1920-1960$ & $\begin{array}{l}\text { Inicia-se com as mudanças citadas que foram aprofundadas } \\
\text { nesse período e termina com a emergência de novos } \\
\text { paradigmas, como a geografia teorética, a educação tecnicista } \\
\text { da nova LDB e o esvaziamento político da geografia escolar. }\end{array}$ \\
\hline $\begin{array}{c}1960 \text { até a atualidade } \\
\text { (início do XXI) }\end{array}$ & $\begin{array}{l}\text { Caracterizado pelas mudanças nas geografias acadêmicas e } \\
\text { escolar, nos métodos de ensino e na LDB. }\end{array}$ \\
\hline
\end{tabular}

Fonte: Adaptado de Souza e Pezzato (2010, p.76).

\footnotetext{
${ }^{3}$ Ainda que não seja o escopo deste artigo, as pesquisas atualmente desenvolvidas sobre o desenvolvimento da ciência geográfica e sua relação com a escola mostram que a influência do discurso neopositivista e neoliberal tensiona a produção do conhecimento geográfico escolar no Brasil. Em alguns momentos, convergem para as teorias do tecnicismo, haja vista a necessidade imposta, pelos sistemas educacionais, de instrumentalizar os estudantes para o uso das tecnologias - sobretudo em uma sociedade da informação. Ver Souza e Juliasz (2020).
} 
Já Tonini (2014), ao examinar o livro didático em sua estrutura de linguagem e em seus novos modos de comunicação, objetivou discutir as transformações pelas quais ele passou no século XX, o que, segundo a autora, acarretou em uma "virada textual" em termos de sua elaboração. Assim, ela faz uma distinção dos livros em: de primeira geração (fim do século XIX até meados do século XX), os quais apresentavam um texto único, coeso e organizado de forma linear/hierárquica, como das obras de Aires de Casal e Delgado de Carvalho; de segunda geração (meados do século XX), quando foram inseridas imagens (mesmo sendo pouco atrativas), representando um deslocamento da centralidade do texto escrito, como o livro de Aroldo de Azevedo; e também os de terceira ou de última geração (ao final do século XX e início do XXI), caracterizados por uma variedade de elementos (que podiam até secundarizar o texto escrito), qualidade editorial e semelhança a uma página de internet. Como exemplos, estão incluídas, nesse caso, as obras de Moreira e Sene e a de Demétrio Magnoli.

\section{UMA PROPOSTA DE PERIODIZAÇÃO PARA OS LIVROS DIDÁTICOS DE GEOGRAFIA: DA FASE PRÉ-INDUSTRIAL À ATUALIDADE}

Diante dessas propostas de periodização e considerando as variáveis eleitas para esse trabalho, discutiu-se a seguir cada uma das cinco fases delimitadas na trilha de pesquisa, que são: 1) período "Pré-industrial", que abarca o final do século XIX com os livros didáticos importados pelo país até os anos 1930; 2) período da década de 1930 até o início do regime militar; 3) período do golpe militar, iniciado em 1964, até a instauração do Programa Nacional do Livro Didático (PNLD) em 1985; 4) período de maturação do PNLD até 2005, dentro do contexto da redemocratização brasileira e de seu processo de avaliação pedagógica; e 5) PNLD atual, focado em avaliações e distribuição em massa de livros, sendo um dos maiores programas, para este propósito, no mundo.

O primeiro período elencado - o qual para fins de denominação foi chamado de "pré-industrial" - é caracterizado pela não-consolidação de um mercado de produção didática nacional, pois os materiais didáticos (os impressos didáticos) eram trazidos da Europa, estabelecendo ainda relações coloniais de produção industrial. A referida prática de importação dos materiais passava pelas editoras e "casas livreiras" nacionais como a Francisco Alves, que editava livros em geral e também textos didáticos (HALLEWELL, 1985). Essa prática de importação tornou-se muito comum por parte do Colégio Pedro II primeiro estabelecimento de ensino brasileiro a prever utilização de livros didáticos -, cujos professores ${ }^{4}$ estimulavam a importação livros europeus como forma de subsidiar o processo de ensino-aprendizagem e estruturar os conteúdos de ensino a partir de referenciais estrangeiros.

Para além da importação desses livros, no final do século XIX, quando da consolidação educacional ainda muito marcada pela Pedagogia tradicional laica, não se conjecturava o estabelecimento de uma Geografia de fato nacional, mesmo que houvessem sido produzidos, em períodos anteriores, estudos e composições de panoramas sobre o território brasileiro a mando do Império. Inclusive, esses materiais foram produzidos por pessoas de renome institucional no Estado brasileiro e que não necessariamente tinham vínculos estritos com a ciência geográfica e tampouco o faziam com uma finalidade pedagógica, como é o caso da "Corografia Brasílica" do padre Manuel

\footnotetext{
${ }^{4}$ Os professores também se consolidavam, em alguns casos, como produtores de livros didáticos, os quais eram baseados em suas aulas.
} 
Aires de Casal, o qual, apesar de tudo, ainda possuía uma filiação com a Geografia Clássica.

A escola brasileira deste momento se apresentava como uma escola para as elites. Tanto que, em muitos momentos, os livros didáticos ainda eram importados e lidos em suas línguas de origem, como o francês. Com isso, os livros didáticos deste primeiro momento estavam compromissados em articular estudos socioterritoriais muito amplos para descrever como estava composto o território brasileiro até então, também porque a construção da nação se colocava como um ideário pedagógico. Numa perspectiva filosófica de educação na qual os aspectos filosófico-científicos estavam em destaque, este material era para ser lido e repassado em sala de aula, sem que se propusessem atividades extraclasse, pois o "protagonismo educacional", nesse contexto, era calcado na figura do professor, estando os estudantes relegados ao papel passivo em uma "educação depositária" (SAVIANI, 2013).

Ensinar geografia, neste período que antecede a relação Estado-produção didática, era ensinar a partir de quadros descritivos da paisagem. E, deste modo, se descrevia, sob a episteme do positivismo lógico, as diferentes paisagens do Brasil, como nestes primeiros estudos de Geografia, que estabeleceram-se como Corografias - estudos descritivos da natureza e da sociedade baseados na "escola alemã de Geografia" (MOREIRA, 2011). O discurso do conhecimento territorial - arrastado até a Pedagogia tecnicista - articulava-se com os modelos de unidades de paisagem, produzindo um livro didático de saber neutro e ordenado, cujo estudante e professor eram externos ao conhecimento que constava no livro didático de então. Era uma Geografia de cunho determinista, pois o meio (natural) aparecia como preponderante ao ser humano na relação N-H-E (MOREIRA, 2014). Assim também, a Geografia tradicional, que é identificada nessa primeira série de materiais didáticos no Brasil, era um modelo geral e causal de apreensão da realidade (SOUZA; JULIASZ, 2020).

A seu modo, o segundo período é marcado pela consolidação da Geografia no Brasil, efervescência dos ideais escolanovistas e avanço do processo de industrialização brasileira, mudança na visualidade dos livros e pela consequente criação de políticas públicas voltadas para a produção e distribuição de obras didáticas. Em primeiro lugar ocorre, pela necessidade da consolidação de cursos de formação de professores premissa básica para os pensadores da Escola Nova e que acabou por ser incorporada ao discurso oficial - o desenvolvimento de Geografia de caráter acadêmico a partir da criação da Universidade de São Paulo (USP), em 1934, e da Universidade Federal do Rio de Janeiro no mesmo ano (MOREIRA, 2011). Isso transforma a base de pensamento geográfico brasileiro por buscar a adoção de outra "escola de pensamento", a francesa, além de que isto também influenciou significativamente a produção didática nacional.

A abrangência desse período localiza-se sob três patamares essenciais: a) o início da relação Estado-produção didática através da Comissão Nacional do Livro Didático (CNLD, fundada em 1934) e campanhas do livro didático subsequentes como a Caldeme e a FENAME, juntamente com o Instituto Nacional do Livro (INL) (FILGUEIRAS, 2011; 2020); b) o desenvolvimento da Geografia brasileira e sua institucionalização acadêmica enquanto um campo do saber; c) o desenvolvimento e amadurecimento das ideias pedagógicas da Escola Nova, a partir do Manifesto dos Pioneiros da Escola Nova de 1932 e seus desdobramentos nas políticas estatais levadas a cabo nesta época, tendo como exemplo a Reforma Gustavo Capanema (1942-1946) (SAVIANI, 2013). 
Característica primaz da relação Estado-produção didática, a estruturação de uma política pública oficial para a produção de livros didáticos vai ao encontro das ideias varguistas conduzidas neste período. A política de estímulo industrial getulista do início do século XX beneficiou a ampliação da indústria de livros didáticos nacionais, já que estes eram, normalmente, importados e/ou produzidos no estrangeiro até o fim do século XIX. Assim sendo, a CNLD estava incumbida de rastrear o modo como passaria a ser produzido o livro didático no Brasil, em observância aos valores morais nacionalistas conduzidos pelo Estado Novo. Em outras palavras, nesse contexto ocorrem importantes eventos considerados nessa pesquisa, o que marca a passagem dos livros didáticos "nãoprofissionalizados" para os livros produzidos a partir de uma ciência de referência já institucionalizada no país e por meio de uma indústria editorial em ascensão.

É também neste período das décadas iniciais do século XX em que ocorre a pulverização do conjunto das ideias pedagógicas da Escola Nova. Calcadas nas teorias psicopedagógicas estadunidenses - especialmente de John Dewey - tal ideário foi amplamente divulgado nas produções de materiais pedagógicos, bem como no "Manifesto dos Pioneiros da Escola Nova", lançado em 1932 (SAVIANI, 2013). Influência esta que persiste ao longo das décadas seguintes, dadas as constantes reedições de manuais pedagógicos produzidos por defensores e divulgadores do escolanovismo nacional, como por exemplo Lourenço Filho (SAVIANI, 2013; SILVA, 2018). Tais ideias fizeram a contraposição àquilo que seus principais autores chamavam de Pedagogia tradicional, cujo expoente institucional foi a Igreja Católica e suas pedagogias jesuíticas colocadas em prática desde a invasão portuguesa ao Brasil, em 1500, e a partir da promulgação da Ratio Studiorum em 1599 (SAVIANI, 2013).

No caso, a Pedagogia Nova não dava centralidade à discussão do protagonismo do professor e do domínio do conhecimento a ser transmitido por ele, atribuindo a responsabilidade e a centralidade do processo educativo sobre o estudante (SOUZA, JULIASZ, 2020). No que tange à ciência geográfica, o período é o de consolidação da Geografia no Brasil, dada sua institucionalização oficial no Ensino Superior. O contexto para sua ocorrência foi favorecido pelas Reformas Capanema que - sob os auspícios do apanágio escolanovista - estavam ligadas à estruturação de cursos de formação docente através de cursos de Ensino Superior, organizados e fornecidos pelo Estado. Em um panorama educacional amplo, a educação nacional acabou por integrar as ideias pedagógicas da Escola Nova, que em sua proposta trazia a estruturação de um sistema nacional de ensino e a necessidade de formação de professores (SAVIANI, 2013).

Esse é também o momento da fundação de cursos como os da Universidade de São Paulo e da Universidade Federal do Rio de Janeiro, que instauram uma matriz geográfica de influência francesa ${ }^{5}$, a qual também serviu como referência à formação de professores para as escolas primárias e secundárias. Assim, a Geografia brasileira nasce da necessidade descritiva do território, tal como foi incorporada ao Estado francês para exaltar o nacionalismo de seu povo. Além disso, a partir da fundação desses cursos, ocorre uma profissionalização da docência em Geografia, já que anteriormente essa disciplina era ministrada por profissionais formados em Direito, Engenharia ou até mesmo por professores leigos (SOUZA; PEZZATO, 2010).

Tal matriz geográfica tinha como princípio a Geografia Regional de Vidal de La Blache, historiador convocado pelo Estado francês para pensar a estruturação da ciência

\footnotetext{
${ }^{5}$ O Curso Superior de Geografia da USP, por exemplo, contou com a participação ativa de Pierre Mombeig e Pierre Deffontaines, geógrafos franceses estruturantes da matriz curricular da Geografia institucional no ensino superior brasileiro.
} 
geográfica daquele país logo após conflitos com a Alemanha, país onde a tradição geográfica estava arraigada ao Estado. Inspirada em modelos iluministas desde E. Reclus, essa Geografia era uma Geografia de descrições do território com base em compartimentos territoriais semelhantes e complementares ("quadros" territoriais) entre si (MOREIRA, 2011).

Produto de seu tempo, o livro didático de Geografia deste momento contém a expressão nacionalista do Estado Novo varguista atrelado ao desenvolvimento da Geografia acadêmica no Brasil. Tais aspectos, então, influenciaram os livros didáticos de Geografia no que se refere às descrições sobre as riquezas e qualidades brasileiras, bem como classificação do território e da paisagem (marcas da geografia lablachiana) com o fito de criar o sentimento de pertencimento do povo ao seu território.

Um dos geógrafos que deram grande contribuição à produção didática deste período foi Aroldo de Azevedo. Com claras vinculações à Geografia Regional francesa, produziu inúmeros livros para as séries do curso normal e colegial, os quais exerceram grande influência no ensino de Geografia durante as décadas de 1930 a 1970 (CAMPOS, 2000). Ele foi um dos responsáveis pela consolidação do paradigma da Terra e o Homem na Geografia escolar brasileira e estruturava seus livros no arquétipo Terra-HomemEconomia, com textos também voltados para a formação patriótica dos alunos. Havia, nesse caso, o evidenciar da positividade quanto às características naturais do Brasil e reforço de um "grande país agrícola", além de apresentar, em seus livros, regionalizações diferentes das de Delgado de Carvalho, pelo fato de este adotar critérios naturais e humanos distintos (AZAMBUJA, 2014).

Ao final dessa fase, que se estende da década de 1930 até o início da década de 1960, tem início o terceiro período, demarcado pelo golpe militar. O período ditatorial é atravessado por: mudanças na política editorial com a criação da Comissão do Livro Técnico e do Livro Didático (COLTED), hegemonia da corrente tecnicista e, no campo geográfico, desenvolvimento da Geografia Teorética que, ao final da década de 1970, passa a ser contestada pelos movimentos de renovação. A partir deste momento, não altera-se somente o paradigma geográfico nacional, mas também se modificam as relações do Estado frente ao livro didático através de influências estrangeiras sustentadas pelos interesses dos governantes militares.

As ligações de produção do livro didático nacional se mesclam às relações do Estado Maior militar, tanto no que se refere à economia quanto à sociedade. A maior aproximação com órgãos estadunidenses, com consequentes ingerências na produção didática, alinha interesses de controle e possibilidade de um maior financiamento editorial nacional. A COLTED, fundada em 1966 e extinta em 1971 (que desencadeou o procedimento de coedição de livros didáticos através do Instituto Nacional do Livro - INL e parcerias com as editoras dos materiais didáticos), alçou a política pública de financiamento da produção didática a um patamar inédito. Com investimentos significativos, as parcerias entre MEC e USAID - órgão estadunidense nascido do contexto da Guerra Fria para controlar os países alinhavados com suas políticas de Estado - tornam esta política uma das mais relevantes no sentido econômico na educação brasileira ( 9 milhões de livros, comprados por 50 milhões de dólares, e distribuídos ao longo de três anos) (FILGUEIRAS, 2011). Em termos de legislação educacional, uma das grandes marcas desse período foi a lei n5692/1971, que estabeleceu, entre outras coisas, a fusão dos conteúdos de Geografia e História na disciplina denominada por Estudos Sociais, o que ocasionou perdas significativas nas identidades científicas destas áreas do conhecimento escolar e também a fusão dos livros das duas disciplinas. 
O contexto geográfico deste momento transforma a Geografia influenciada pelo escolanovismo em uma Geografia dos dados e das quantificações. A eclosão do movimento intitulado de New Geography nos Estados Unidos - no Brasil, reconhecido enquanto o movimento da Geografia Teorética - transforma a Geografia Regional francesa em uma localização espacial aplicada à quantificação geográfica. Evidentemente, assim como em outros momentos, ocorreram movimentos de contestação à produção científica dominante de sua contemporaneidade. Entretanto, particularmente neste momento, a forte especialização da Geografia como uma "ciência do território" foi desenvolvida em consubstanciação a uma política de reconhecimento territorial levada a cabo pelos sucessivos governos militares. Marca desta Geografia era a ênfase em processos mnemônicos e um forte distintivo impresso pelos dados estatísticos, determinantes para a organização socioespacial. O discurso acadêmico-estatístico se evidenciava nas médias/índices/elementos quantitativos que se tornam conteúdo geográfico, na concepção de espaço geográfico como um campo de ação do Estado e na difusão de uma "Geografia em perspectiva", a qual não altera ou transforma o ambiente (SOUZA; JULIASZ, 2020).

Já no campo pedagógico e educacional em geral ascende, como proposta, a Pedagogia Tecnicista. Um ponto possível de intersecção entre a Pedagogia e a Geografia Tecnicistas são os exercícios de reforço e repetição, como modo de fixação conteúdos por meio da memorização. A Pedagogia Tecnicista trazia, em suas raízes epistemológicas, a psicopedagogia do comportamentalismo, difundida por pensadores como Skinner (SKINNER, 1982) nos Estados Unidos. A proposta pedagógica do tecnicismo considerava o desenvolvimento escolar pelo comportamento dos estudantes, que deveriam ser premiados ou repreendidos por suas ações escolares no cumprimento de ordens específicas para execução de tarefas de aprendizagem.

A característica principal dos livros didáticos nesse caso era também a marca primordial do processo educacional pensado pela Pedagogia Tecnicista: a massificação da instrução e do acesso ao conhecimento, instaurada por livros que aplicassem técnicas de ensino mnemônico. O paradigma do ensino técnico-profissionalizante e a preponderância do discurso do "território nacional" nos livros didáticos de Geografia (SOUZA, 1991) também são elementos centrais deste período. E, apesar dos livros sofrerem alterações quanto a presença de textos mais diretos, simplificados e superficiais, com a inclusão de exercícios e estudos dirigidos à estrutura, houve uma manutenção do arquétipo NaturezaHomem-Economia ou Terra-Homem-Economia como norteador da organização dos conteúdos, além de que ocorreu um empobrecimento do livro didático conjuntamente ao aumento da diversidade de autores, livros e editoras (AZAMBUJA, 2014).

Quanto ao quarto período definido, ele apresenta inúmeras características que o distingue dos períodos anteriores, o que não significa que ele seja homogêneo no que tange às correntes pedagógicas, políticas educacionais (gerais ou voltadas especificamente para os livros didáticos), matrizes do pensamento geográfico ou organização dos livros. Pelo contrário, trata-se de um novo contexto marcado pela pluralidade, apesar de que alguns elementos o tornam singular. Em primeiro lugar, a década de 1980, que data o início dessa fase, é atravessada pelo processo de redemocratização, início do Programa Nacional do Livro Didático (em 1985), desenrolar da renovação crítica na Geografia (que não esteve circunscrita apenas à academia), emergência de novas correntes pedagógicas e remodelação de antigas tendências (sob a designação do prefixo "neo"), novas visualidades do livro didático e expansão da produção editorial no Brasil. 
Os livros didáticos deste período já atravessam relativa estabilidade quanto ao desenvolvimento tecnológico na linha de produção, incorporando novidades produtivas ao material desenvolvido até então. O aumento na qualidade de impressão - especialmente com o advento de softwares computadorizados para editoração dos livros didáticos permitiu aos materiais um salto qualitativo em relação às dificuldades encontradas no período anterior. Um exemplo marcante são as novas possibilidades de diagramação de páginas, apontando para uma leitura focada e direcionada, a depender do nível de aprendizagem dos estudantes. As imagens destes livros didáticos também sofrem considerável melhoria quanto ao avanço das técnicas de inserção das mesmas nas páginas dos livros (MUNAKATA, 1997).

Entretanto, cabe ressaltar que nem sempre a melhoria na qualidade produtiva dos livros didáticos foi incorporada sob o intuito de um olhar pedagógico. Em muitos casos, imagens e novas diagramações (especialmente nas áreas de alfabetização e letramento, por exemplo) foram utilizadas como meras ilustrações, dignas do apelido de "Disneylândia pedagógica" (MUNAKATA, 1997). Apesar disso, de acordo com Azambuja (2014), os livros didáticos começam a ter um conteúdo mais interpretativo e crítico, incluindo novas concepções e temáticas e evidenciando uma renovação nos métodos, conceitos e temas. Outras perspectivas na ciência de referência também passaram a compor os livros didáticos a partir do processo de renovação crítica da Geografia. Entre elas estão as discussões sobre temáticas socioespaciais, preocupações ambientais e mundo do trabalho. Como exemplos mais específicos dessas mudanças, os livros dessa época ultrapassaram as concepções de espaço como uma base física (suporte/palco) da ação humana para uma leitura mais integrada, baseada em novas concepções de espaço geográfico, e a adoção de classificações climáticas ancoradas nos pressupostos na Climatologia dinâmica, em substituição às classificações da Climatologia estática/tradicional (AZAMBUJA, 2014).

A preocupação com sua qualidade pedagógica tensionou as discussões no MEC e no FNDE, recém alçado à condição de organizador da política nacional de livros, com atenção para as questões pedagógicas das páginas do livro - o que toma corpo na década final do século XX e adentra o século XXI como uma das principais características do que costumou chamar-se de Programa Nacional do Livro Didático (PNLD). Normalmente reconhecido como um dos maiores programas públicos de distribuição de livros didáticos do mundo (CASSIANO, 2007), o PNLD é o ápice na história da relação estatal de produção didática e da consolidação de uma política pública para pensar a produção, distribuição e financiamento a nível nacional, a qual empreende esforços para que todo território do país tenha acesso aos livros didáticos - e, deste modo, conhecimento científico - nas escolas públicas.

É também com o PNLD que se fortalecem as sucessivas avaliações, consolidadas como parte essencial do programa e fortemente articuladas com a universidade pública desde o início do século XXI (SPOSITO, 2006). Entretanto, em um primeiro momento, a avaliação profunda dos conteúdos dos livros era preterida a despeito de uma focalização do objetivo do programa: a citada abrangência territorial de livros didáticos.

Assim, a mercadoria livro didático chega ao século XXI como uma "commodity educacional", importante para o desenvolvimento de estratégias de empresas privadas, que tem como exemplo a concentração em torno de um oligopólio educacional no setor (CASSIANO, 2007; 2016). A reunião de editoras de livros didáticos diferentes sob os interesses de grupos educacionais atuantes em várias frentes da educação é resultado de um maior investimento progressivo de valores no PNLD e que garante o mercado editorial 
para futuras edições do PNLD (BAIRRO, 2017), resultando assim na referida concentração oligopolista do setor didático nacional. Por fim, como modo de sintetizar a proposta, elaborou-se um quadro analítico:

Quadro 2. Proposta de periodização para o livro didático no Brasil (final do séc. XIX- início do século XXI)

\begin{tabular}{|c|l|}
\hline Período & \multicolumn{1}{|c|}{ Características } \\
\hline 10 Período (fim do séc. XIX-1938) & $\begin{array}{l}\text { "Pré-Industrial", anterior à criação da CNLD. Geografia não- } \\
\text { constituída como curso superior. Pedagogia Tradicional. }\end{array}$ \\
\hline 20 Período (1938-1964) & $\begin{array}{l}\text { Início da relação oficial Estado-livro didático. Maturidade da CNLD } \\
\text { e outras Campanhas do Livro. Fundação da Geografia do Ensino } \\
\text { Superior Brasileiro. Pedagogia Nova (escolanovismo). }\end{array}$ \\
\hline 3o Período (1964-1985) & $\begin{array}{l}\text { Ditadura Militar. Ampliação de investimentos na produção de livros } \\
\text { didáticos, via COLTED/FENAME/coedição. Pedagogia e } \\
\text { Geografia Tecnicistas ("apostilamento" dos materiais). }\end{array}$ \\
\hline 4o Período (1985-2005) & $\begin{array}{l}\text { Primeira fase do PNLD. Ampliação do acesso aos materiais. } \\
\text { Implementação dos procedimentos avaliativos e pedagógicos dos } \\
\text { livros didáticos. Pluralismo epistemológico. }\end{array}$ \\
\hline 5o Período (2005-) & $\begin{array}{l}\text { Segunda fase do PNLD. Maturação dos processos avaliativos. } \\
\text { Consolidação do oligopólio da produção didática brasileira. } \\
\text { Neotecnicismo, neoescolanovismo, neoconstrutivismo. Geografia } \\
\text { "pós-moderna". }\end{array}$ \\
\hline
\end{tabular}

Fonte: Elaboração dos Autores, 2021.

\section{CONSIDERAÇÕES FINAIS}

Este artigo tratou das mudanças pedagógicas, geográficas e no programa de distribuição de livros didáticos no Brasil desde o fim do século XIX até a contemporaneidade, com o objetivo de estabelecer uma subdivisão têmporo-histórica da produção de livros didáticos. Produção esta que iniciou-se com a relação entre Estado e livro didático na consolidação da CNLD (em 1938), consequência do estreitamento das relações editoriais e estatais e de políticas públicas para expansão de ideologias nacionalistas para o povo brasileiro naquele momento.

Já na contemporaneidade desta produção, ela é marcada por uma Geografia que enseja a superação das críticas realizadas pela ciência geográfica no período anterior. Retomando aspectos da Geografia Tecnicista da ditadura militar, as geografias contemporâneas retratam uma sociedade tida enquanto movimento de superação da modernidade (logo, "pós-moderna"), como uma "ciência de identificação" de grupos. Também sua pedagogia busca retomar, de movimentos anteriores, elementos coadunantes com as perspectivas tecnicistas.

Neste trabalho também foi empreendido um esforço para a organização de uma proposta de periodização que abarcasse todos os três principais aspectos da produção de livros didáticos de Geografia no Brasil, ou seja, o desenvolvimento do ideário geográfico, pedagógico e da política pública de distribuição de livros didáticos, já que esses três campos de análise, ao longo do tempo, se imbricaram. O surgimento de teorias pedagógicas diferenciadas influenciou (em alguns casos) diretamente nos aspectos de produção dos livros didáticos, o que também aconteceu a partir do avançar epistemológico da ciência geográfica. Já a análise da política pública mostrou-se importante para o alcance 
extensivo das duas primeiras determinantes, visto que seu principal foco se torna a distribuição em massa dos materiais para as escolas públicas brasileiras.

Em suma, a proposta apresentada não enseja um consenso no campo de pesquisa. Porém, coloca-se como importante para o avançar do campo de pesquisa em livros didáticos dentro da Geografia, para além dos moldes já colocados, focados mormente em análises de conteúdo contido nestes materiais. E, por isso, consideramos que a política pública de distribuição de livros didáticos, a qual possui mais de 80 anos de existência desde a CNLD, deve ser um elemento importante a ser considerado, pois é a principal forma de alcance do conhecimento científico em um país de desigualdades socioespaciais tão intensas como é o caso do Brasil. Por último, a periodização proposta reafirma essas perspectivas e advoga pela ampliação do debate científico-escolar sobre possíveis pontos de interligação entre o conhecimento geográfico, as teorias e ideias pedagógicas e as políticas públicas educacionais.

\section{NOTA}

Agradecimento ao Conselho Nacional de Desenvolvimento Científico e Tecnológico (CNPq) pela Bolsa de Mestrado concedida ao primeiro autor deste artigo.

\section{REFERÊNCIAS}

ALBUQUERQUE, M. A. M. Livros didáticos e currículos de Geografia: uma história a ser contada. In: CASTROGIOVANNI, A. C. [et al] (Orgs). O ensino de geografia e suas composições curriculares. Porto Alegre: Mediação, 2014, Cap.11, p.161-174.

AZAMBUJA, L. D. O livro didático e o ensino de Geografia do Brasil. Revista Brasileira de Educação em Geografia, Campinas, v. 4, n. 8, p.11-33, 2014. Disponível em: http://revistaedugeo.com.br/ojs/index.php/revistaedugeo/article/view/180/131. Acesso em: 28 dez. 2020.

BAIRRO, G. P. O contexto da produção didática no Brasil: o financiamento através do Programa Nacional do Livro Didático (PNLD). 2017. 87 f. Trabalho de conclusão de curso (bacharelado - Geografia) - Universidade Estadual Paulista Júlio de Mesquita Filho, Instituto de Geociências e Ciências Exatas, 2017. Disponível em: http://hdl.handle.net/11449/157038.

BOURDIEU, P. Coisas ditas. São Paulo: Brasiliense, 2004.

CAMPOS, R. R. A Geografia de Aroldo de Azevedo. Geografia, Rio Claro, Vol. 25(2): 5397, agosto/2000.

CASSIANO, C. C. F. O mercado do livro didático no Brasil: da criação do Programa Nacional do Livro Didático (PNLD) à entrada do capital internacional espanhol (1985-2007). 2007. 252 f. Tese (Doutorado em Educação) - Pontifícia Universidade Católica de São Paulo, São Paulo, 2007.

O mercado do livro didático no Brasil do século XXI: a entrada do capital espanhol na educação nacional. São Paulo: Unesp, 2016. 
CHARTIER, R. A história cultural entre práticas e representações. Lisboa (Portugal): DIFEL, 2002.

CHERVEL, A. História das disciplinas escolares: reflexões sobre um campo de pesquisa. Revista Teoria e Educação, Porto Alegre, n.2, 1990.

CHOPPIN, A. Los manuales escolares de ayer a hoy: el ejemplo de Francia. Historia de la educación - revista interuniversitaria, Universidade de Salamanca, ํo 19, p.13-36, 2000.

FILGUEIRAS, J. M. Os processos de avaliação de livros didáticos no Brasil: (19381984). 2011. 263f. Tese (Doutorado em Educação) - Pontifícia Universidade Católica de São Paulo, São Paulo, 2011.

Por uma nova Geografia Escolar: a avaliação dos programas e livros didáticos de geografia pela Caldeme. Educação Unisinos, v. 24, 2020.

HALLEWELL, L. O livro no Brasil: sua história. São Paulo, T.A. Queiroz/Edusp, 1985.

MOREIRA, R. O discurso do avesso: para a crítica da Geografia que se ensina. São Paulo: Contexto, 2014, 189p.

O pensamento geográfico brasileiro, vol. 1: as matrizes clássicas originárias. (2 $2^{\mathrm{a}}$ ed). São Paulo: Contexto, 2011.

MUNAKATA, K. O livro didático: alguns temas de pesquisa. Revista Brasileira de História da Educação. Campinas, SP, v.12, n.3 (30), p.179-197, set./dez. 2012.

Produzindo livros didáticos e paradidáticos. 1997. 223 f. Tese (Doutorado em Educação) - Pontifícia Universidade Católica de São Paulo, São Paulo, 1997.

PINHEIRO, A. C. O ensino de geografia no Brasil: catálogo de dissertações e teses (1967-2003). Goiânia: Editora Vieira, 2005.

SAVIANI, D. História das ideias pedagógicas no Brasil. 4 ed. Campinas, SP: Autores Associados, 2013, 472p.

SENE, J. E. Livro didático como produto da Geografia Escolar: obra menor? Revista Brasileira de Educação em Geografia, Campinas, v. 4, n. 7, p. 27-43, jan./jun., 2014. Disponível em: $<$ http://www.revistaedugeo.com.br/ojs/index.php/revistaedugeo/article/view/143/120>. Acesso em: 10 dezembro 2020.

SILVA, V.B. Livros que ensinam a ensinar: um estudo sobre os manuais pedagógicos brasileiros (1930-1971). Curitiba: Appris, 2018.

SKINNER, B. F. Sobre o behaviorismo. São Paulo: Cultrix/EDUSP, 1982.

SOUZA, J. G.; JULIASZ, P. C. S. Geografia: ensino e formação de professores. Marília: Lutas Anticapital, 2020, 200p. 
SOUZA, J. G. O conceito de trabalho no livro didático de Geografia. Presidente Prudente: FCT/UNESP. 1991, 155p.

SOUZA, T. T.; PEZZATO, J. P. A geografia escolar no Brasil, de 1546 até a década de 1960. In: GODOY, P. R. T. (Org.) História do pensamento geográfico e epistemologia em Geografia. São Paulo: Cultura Acadêmica, 2010, Cap. 4, p.71-88.

SPOSITO, M. E. B. (Org.). Livros Didáticos de História e Geografia: avaliação e pesquisa. São Paulo: Cultura Acadêmica, 2006.

TONINI, I. M. Livro didático: textualidades em rede? In: TONINI, Ivaine Maria et al. 0 ensino de Geografia e suas composições curriculares. Porto Alegre: Mediação, 2014. Cap. 10. p. 149-159. 